\title{
Comparative investigation on the failure modes of natural kenaf/epoxy reinforced composite hexagonal tubes
}

\begin{abstract}
This study aims to investigate failure mode response of woven natural kenaf/epoxy composite hexagonal tubes subjected to an axial and lateral quasi-static crushing test. The hexagonal composite tubes were prepared by the hand lay-up technique using a variety of hexagonal angles $40^{\circ}, 50^{\circ}$, and $60^{\circ}$. The result showed that hexagonal composite tubes under an axial compression test exhibited few failure modes such as, the transverse crack failure mode . Splaying failure mode and local buckling failure mode respectively, whereas the tubes under lateral test only exhibited longitudinal fracture.
\end{abstract}

Keyword: Failure mode; Natural fiber; Crashing behavior 